\title{
PENGARUH KONFLIK PEKERJAAN-KELUARGA TERHADAP KEPUASAN KERJA DAN KEPUASAN HIDUP (STUDI PADAPEREMPUAN ETNIS BALI YANG BEKERJA DI KOTA MATARAM)
}

\author{
Siti Nurmayanti ${ }^{1}$, Dwi Putra Buana Sakti², \\ I Nyonan Nugraha Ardana Putra ${ }^{3}$, Laila Wardani ${ }^{4}$ \\ ${ }^{I}$ Fakultas Ekonomi dn Bisnis,Mataram, mayaramli24@gmail.com \\ ${ }^{2}$ Fakultas Ekonomi dan Bisnis, Mataram, dwiputrabs39@gmail.com \\ ${ }^{3}$ Fakultas Ekonomi dan Bisnis, Mataram,ibobid@yahoo.com \\ ${ }^{4}$ Fakultas Ekonomi dan Bisnis, Mataram, elawardani.mtr@gmail.com
}

\begin{abstract}
ABSTRAK
Etnis Bali, dimanapun mereka bermukim baik individu ataupun berkelompok akan selalu melaksanakan kehidupannya sebagaimana yang ada di daerah leluhurnya yaitu Pulau Bali. Pelaksanaan tata cara berkehidupan yang telah diatur dan diwariskan oleh leluhur etnis Bali berlaku bagi laki-laki dan perempuan. Tentu saja hal ini menambah peran bagi perempuan etnis Bali, terlebih bagi mereka yang bekerja. Perempuan etnis Bali yang bekerja dihadapkan pada pemenuhan kewajiban dalam berbagai peran. Kondisi ini apabila tidak dapat diselaraskan, dapat menimbulkan konflik Konflik yang timbul dapat berupa konflik pekerjaan-keluarga yang dapat berdampak pada kepuasan kerja dan kepuasan hidup.

Penelitian ini bertujuan untuk menganalisis pengaruh konflik pekerjaan keluarga terhadap kepuasan kerja perempuan etnis Bali yang bekerja dan menganalisis pengaruh konflik pekerjaan keluarga terhadap kepuasan hidup perempuan etnis Bali yang bekerja. Paradigma yang digunakan dalam penelitian ini adalah paradigma positivis dengan metode kuantitatif sebagai desain yang tepat untuk mencapai tujuan penelitian. Melalui pendekatan ini peneliti menyebarkan kuesioner terstruktur yang ditujukanuntukmemperoleh data yang akandianalisis. kepada 149 orang respondenperempuan etnis Bali di Kota Mataram yang bekerja, Semua data dianalisis menggunakan Partial Least Squre (PLS).Hasil penelitian menunjukkan konflik pekerjaan keluarga pengaruh negatif dan signifikan terhadap kepuasan kerja perempuan etnis Bali yang bekerja dan konflik pekerjaan keluarga berpengaruh negatif dan signifikan terhadap kepuasan hidup perempuan etmnis Bali yang bekerja.
\end{abstract}

Kata Kunci: konflikpekerjaan-keluarga, kepuasan kerja, kepuasan hidup

\section{ABSTRACT}

The Balinese, wherever they live either individually or in groups, will always carry out their lives as in the ancestral area of Bali Island. Implementation of the livelihood arrangements that have been regulated and inherited by Balinese ethnic ancestors apply to both men and women. Of course this adds a role for Balinese women, especially to those who work. Balinese ethnic women who work are faced with fulfillment of obligations in various roles. This condition if it can not be aligned, can lead to conflict Conflict that arise can be a work-family conflict that can impact on job satisfaction and life satisfaction.

This study aims to analyze the influence of conflict of family work on job satisfaction of ethnic Balinese women who work and analyze the influence of conflict of family work to life satisfaction of Balinese ethnic women who work.. The paradigm used in this research is a positivist paradigm with quantitative method as the right design for achieve research objectives. Through this approach the researcher distributed a structured questionnaire aimed at obtaining data to be analyzed. to 149 Balinese women respondents in Mataram working, All data were analyzed using Partial Least Squre (PLS). The result of the research shows that the conflict of family work negatively and significantly influence the work satisfaction of the working ethnic Balinese women and the conflict of family work have a negative and significant effect to the satisfaction of life of Balinese ethnic women who work.

Keywords: work-family conflict, job satisfaction, life satisfaction 


\section{PENDAHULUAN}

Masalah yang dihadapi perempuan dalam usahanya untuk menyeimbangkan antara peran pekerjaan dan peran keluarga tampaknya adalah sebuah masalah yang terjadi secara global. Menurut teori peran, perempuan dari budaya apapun kemungkinan besar akan mengalami konflik ketika mereka berusaha untuk menjalankan peran tradisional mereka dalam keluarga sekaligus peran modern mereka sebagai pekerja (Wafula, 2010). Teori peran menyatakan bahwa sebuah kelompok biasanya memiliki norma-norma yang harus dipatuhi para anggotanya, dan para anggota kelompok biasanya mematuhi norma-norma ini karena adanya ganjaran yang diberikan ketika mereka patuh dan ada hukuman yang diberikan ketika mereka tidak patuh (Carlson, Kacmar \& Stepina, 1995 dalam Wafula, 2010).

Konflik peran pada perempuan dengan etnis/budaya tertentu telah menjadi kajian yang cukup menarik. Salah satunya adalah kajian pada perempuan etnis Bali yang beragama Hindu. Etnis Bali dimanapun mereka bermukim baik individu ataupun berkelompok akan selalu melaksanakan kehidupannya sebagaimana yang ada di daerah leluhurnya yaitu Bali. Mereka yang merantau dan menetap di daerah tertentu akan senantiasa hidup dengan sistim yang telah melekat dan mendarah daging dalam diri mereka. Demikian pula halnya dengan perempuan Bali yang telah lama menetap di Mataram. Ditinjau dari sistem sosial yang djalankan, mereka masih tetap mempertahankan dan melaksanakan sistem sosial sebagaimana layaknya leluhur mereka di Pulau Bali.

Dilihat dari aspek kehidupan berorganisasi, etnis Bali yang menetap di Mataram masih tetap melaksanakan sistem organisasi seperti yang terdapat di Pulau Bali. Yudarta mengutip Suyadnya (2006) menyebutkan bahwa komunitas etnis Bali di Pulau Lombok mengorganisasikan diri kedalam wadah berbentuk banjar-banjar, suatu organisasi tradisional yang ada pada etnis Bali. Wujud kehidupan sosial lainnya yang juga diterapkan oleh etnis Bali - di Pulau Lombok pada umumnya dan Kota Mataram khususnya - terlihat pada pelaksanaan berbagai upacara adat sebagaimana yang termuat dalam Panca Yadnya. Mereka mengamalkan keseluruhannya dalam kehidupan sehari-hari sesuai dengan apa yang diperoleh dan diwariskan oleh para leluhur. Budaya dan adat istiadat Bali mewajibkan masyarakatnya baik laki-laki maupun perempuan mengikuti kegiatan-kegiatan yang berhubungan dengan adat dan agama sebagaimana yang diatur dalam awig-awig yang dibuat dan disepakati bersama (Sistu dalam Saskara et all, 2012).

Adanya multiperan yang dijalankan oleh perempuan Bali sangat dimungkinkan untuk mengalami konflik (Sunasri dalam Saskara et all, 2012). Konflik yang dihadapi adalah konflik antar peran yang disebabkan oleh kompleksitasnya peran kehidupan yang dijalani oleh perempuan Bali. Konflik antar peran tersebut yakni konflik pekerjaankeluarga. Konflik pekerjaan keluarga ditemukan dapat memengaruhi kepuasan kerja dan kepuasan hidup dari para perempuan, khususnya pada perempuan etnis Bali yang menikah dan bekerja. Sehingga hal ini menjadi menarik untuk diteliti bagaimana perempuan Bali yang bekerja menyeimbangkan peran-peran tersebut dalam kehidupan mereka.

Berdasarkan paparan di atas maka permasalahan penelitian apakah terdapat pengaruh konflik pekerjaan-keluarga terhadap kepuasan kerjapada perempuan etnis Bali di Kota Mataram yang bekerja dan apakah terdapat pengaruh konflik pekerjaan-keluarga terhadap kepuasan hidup pada perempuan etnis Bali di Kota Mataram yang bekerja.Sehingga penelitian ini ditujukan untuk menganalisis pengaruh konflik pekerjaankeluarga terhadap kepuasan kerjapada perempuan etnis Bali di Kota Mataram yang bekerja 
dan menganalisis pengaruh konflik pekerjaan-keluarga terhadap kepuasan hidup pada perempuan etnis Bali di Kota Mataram yang bekerja

\section{Penelitian Terdahulu}

\section{TINJAUAN TEORITIS}

Tema penelitian dengan kajian mengenai konflik pekerjaan keluarga yang dikaitkan dengan kepuasan kerja dan kepuasan hidup sudah banyak dilakukan. Namun tema ini tetap menarik untuk dikaji oleh para peneliti. Terlebih ketika penelitian tersebut dikaitkan dengan budaya atau etnis tertentu.

Penelitian yang dilakukan oleh Saskara et all (2012) menemukan bahwa konflik peran pada perempuan Bali dipengaruhi oleh budaya dan lingkungan kerja. Perilaku perempuan Bali yang bekerja di sektor publik, akan mengorbankan kegiatan rutinnya di tempat kerja untuk berpartisipasi pada kegiatan adat terutama dalam upacara kematian di lingkungan banjarnya. Penelitian yang dilakukan oleh Kesumaningsari dan Simarmata (2014) pada karyawati Bali yang bekerja sebagai pegawai bank menemukan bahwa perempuan Bali/Hindu yang bekerja sebagai karyawan bank mengalami konflik pekerjaan keluarga dan konflik tersebut berpengaruh pada work engagement karyawan. Sementara Diputra dan Lestari (2015) menemukan bahwa perempuan Hindu yang menjalani peran ganda mengalami stres yang bersumber dari keluarga dan lingkungan.

Zhao, Qu dan Hailin (2009), Qu dan Zhao (2012) dalam penelitiannya terhadap manajer penjualan hotel di Cina menemukan bahwa konflik pekerjaan keluarga berpengaruh terhadap kepuasan kerja dan kepuasan hidup. Sementara Seng, Bujang dan Ahmad (2009) menemukan bahwa konflik pekerjaan keluarga berpengaruh pada kepuaan kerja dan kepuasan hidup pada perempuan di Malaysia. Sementara Hasan (2010) menemukan bahwa orang Malaysia mengalami konflik pekerjaan keluarga yang berpengaruh terhadap kepuasan kerja dan kepuasan hidup. Wafula (2010) melakukan penelitian pada guru perempuan dari budaya kolektivitas menemukan bahwa konflik pekerjaan keluarga berpengaruh terhadap kepuasan kerja.

\section{Konflik Pekerjaan Keluarga}

Teori konflik menyatakan bahwa pengharapan peran dari ranah keluarga atau ranah pekerjaan bisa bertentangan satu dengan lain sehingga menimbulkan norma dan pengharapan yang berbeda-beda (Burke, 1986; Evans \& Bartolome, 1984, Zedeck \& Mosier, 1990 dalam Michel \& Hargis, 2008) dan karenanya peningkatan pada pelaksanaan peran di ranah yang satu (pekerjaan) akan menurunkan pelaksanaan peran di ranah satunya (keluarga), karenanya konflik pekerjaan-keluarga dapat terjadi.

Konflik pekerjaan keluarga (WFC) adalah istilah yang seringkali digunakan untuk menggambarkan konflik antara ranah pekerjaan dan ranah keluarga. Kahn, Wolfe, Quinn, Snoek dan Rosenthal (1964 dalam Bruck et al., 2002) mendeskripsikan konflik pekerjaankeluarga sebagai sebuah jenis konflik antar peran (interrole conflict) dimana tuntutan dari peran kerja mengalami konflik dengan tuntutan dari peran keluarga. Kemudian Renshaw (1976 dalam Bruck et al., 2002) memandang bahwa konflik pekerjaan-keluarga adalah disebabkan oleh interaksi antara stress dalam ranah keluarga dan ranah pekerjaan. Sementara Greenhaus dan Beutell (1985) mendefinisikan konflik pekerjaan keluarga sebagai "suatu jenis konflik atau perselisihan antar peran dimana tekanan peran dari ranah pekerjaan dan ranah keluarga adalah tidak selaras satu sama lain dalam beberapa artian tertentu". Tanggung jawab didalam pekerjaan dan keluarga jelas adalah hal yang sangat penting bagi sebagian besar individu, namun jika dilakukan bersamaan, dua tanggung 
jawab ini seringkali menghasilkan tuntutan-tuntutan yang tidak selaras satu sama lain (Boles et al., 1997 dalam Hsu, 2011).

\section{Kepuasan kerja}

Pembahasan mengenai kepuasan kerja perlu didahului dengan penegasan bahwa masalah kepuasan kerja bukanlah hal yang sederhana baik dalam arti konsep maupun dalam arti analisisnya, karena "kepuasan" mempunyai konotasi yang beraneka ragam. Meskipun demikian tetap relevan mengatakan bahwa kepuasan kerja merupakan cara pandang seseorang, baik yang bersifat positif maupun negatif tentang pekerjaannya (Siagian, 2003). Kepuasan kerja didefinisikan di akhir era 1990an oleh Spector (1997 dalam Bruck et al, 2002) sebagai sebuah variabel sikap/atitudinal, yaitu "tingkat sejauh mana orang merasa suka/puas atau tidak suka/tidak puas terhadap pekerjaan mereka”. Kepuasan kerja adalah salah satu konstruk yang telah sering digunakan untuk mendeskripsikan kondisi kerja, terutama karena kepuasan kerja memiliki hubungan signifikan dengan variabel-variabel lain. Locke (1969 dalam Bruck et al., 2002) telah mendefinisikan kepuasan kerja sebagai tingkat sejauh mana pengharapan yang dimiliki individu tentang pekerjaan adalah sesuai dengan yang diterimanya secara aktual dari pekerjaan.

Kepuasan kerja seseorang pada dasarnya tergantung kepada perbedaan antara harapan, kebutuhan atau nilai dengan apa yang menurut perasaannya atau persepsinya telah diperoleh atau dicapai melalui pekerjaannya. Seseorang akan merasa puas jika tidak ada perbedaan antara yang diinginkan dengan persepsinya atas kenyataan, karena batas minimum yang diinginkan telah terpenuhi.

\section{Kepuasan Hidup}

Diener, Emmons, Larsen, \& Griffen (1985) mengemukakan bahwa kepuasan hidup merupakan penilaian secara kognitif dimana seseorang membandingkan keadaannya saat ini dengan keadaan yang dianggapnya sebagai standar ideal. Apabila semakin kecil perbedaan antara apa yang diharapkan dengan apa yang dicapai oleh individu maka semakin besar kepuasan hidup seseorang. Individu akan berpatokan pada kepercayaan atau sikapnya dalam menilai kehidupannya dan menilai apakah situasi dan kondisi dalam kehidupannya positif dan memuaskan (Schimmack, Pavot dalam Eid \& Larsen, 2008). Sementara Michalos (dalam Amat \& Mahmud, 2009) menyatakan bahwa kepuasan hidup melibatkan berbagai konstruk yang diperlukan seseorang untuk menilai berbagai aspek kehidupannya seperti kesehatan, keuangan, pekerjaan, serta hubungan interpersonalnya. Tetapi kebanyakan masyarakat meletakkan berbagai nilai tersebut terhadap salah satu aspek saja berdasarkan kriteria-kriteria yang ditetapkannya sendiri. .

Individu yang memiliki kepuasan hidup yang tinggi adalah individu yang memiliki tujuan penting dalam hidupnya dan berhasil untuk mencapai tujuan tersebut. Orang yang mendapat skor tinggi pada kepuasan hidup biasanya memiliki keluarga dekat dan dukungan dari teman-teman, memiliki pasangan romantis, memiliki pekerjaan atau kegiatan bermanfaat, menikmati rekreasi, dan memiliki kesehatan yang baik. Mereka 
merasa bahwa hidup ini bermakna, serta memiliki tujuan dan nilai-nilai yang penting bagi mereka. Individu yang puas akan kehidupannya adalah individu yang menilai bahwa kehidupannya mungkin memang tidak sempurna tetapi segala sesuatu berjalan dengan baik, mereka mempunyai keinginan untuk berkembang, dan menyukai tantangan.

\section{METODE PENELITIAN}

Penelitian ini merupakan penelitian kausalitas yang ditujukan untuk menguji pengaruh konflik pekerjaan-keluarga pada perempuan etnis Bali di Kota Mataram terhadap kepuasan kerja dan kepuasan hidup. Populasi target penelitian adalah perempuan etnis Bali di Kota Mataram. Populasi terjangkau penelitian adalah perempuan etnis Bali di Kota Mataram yang bekerja yang memenuhi kriteria: (1) Telah menikah; (2) Tinggal dengan suami yang bekerja; (3) Memiliki anak minimal satu orang, dan (4) Telah bekerja minimal selama 1 tahun.

Ukuran sampel (sample size) yang ditetapkan pada penelitian ini adalah 150 perempuan etnis Bali di Kota Mataram yang bekerja Data yang digunakan adalah data primer, meliputi data yang berhubungan dengan pernyataan responden terhadap konflik pekerjaan-keluarga, kepuasan kerja dan kepuasan hidup. Data primer diperoleh dari responden melalui pengisian kuesioner yang telah disiapkan. Metode Survey digunakan untuk memperoleh data melalui penyebaran kuesioner terstruktur. Data akandianalisismenggunakanPartial Least Squere (PLS).

\section{HASIL DAN PEMBAHASAN}

Karakteristik responden berdasarkan usia menunjukkan bahwa responden perempuan etnis Bali yang bekerja berumur antara 20 sampai 30 tahun. Perempuan dalam tahap umur 20-30 tahun berada dalam tahun transisi awal kedewasaan (17-28 tahun), kemudian umur 30-40 tahun adalah tahap kemapanan, Selama tahun-tahun awal masa transisi, sebagian besar wanita, sangat sibuk untuk mempersiapkan masa menikah. Perhatian utama para wanita adalah untuk mencapai kesetabilan pada awal pernikahan mereka, sehingga investasi mereka pada pekerjaan dalam tahap ini tidak sesignifikan seperti pria. Sikap wanita terhadap pekerjaan pada tahap ini hanya melibatkan komitmen untuk menyelesaikan pekerjaan-pekerjaan yang dianggap penting. Mereka kurang berusaha untuk membangun komitmen demi untuk mendapatkan sebuah jabatan profesional yang bermanfaat untuk kepentingan jangka panjang (Gallos, 1989 dalam Waskito \& Irmawati, 2007).Tahap selanjutnya bagi perempuan adalah periode membangun kehidupan berkeluarga yang membutuhkan komitmen yang kuat. Sebagian besar wanita dalam tahap ini mengeluarkan lebih banyak energi daripada pria untuk membesarkan anak. Misalnya, mereka harus sangat perhatian terhadap pertumbuhan anak, terutama mencarikan sekolah anak mereka dari SD ke SMP.

Tingkat Pendidikan responden sebagian besar berpendidikan SLTA (46\%), kemudian strata satu (32\%). Dengan tingkat pendidikan yang cukup, perempuan etnis Bali diharapkan dapat menjalankan peran mereka dengan baik, di pekerjaan maupun di rumah. 
Menurut masa kerja, 64\% responden perempuan etnis Bali memiliki masa kerja 1-10 tahun. Hal ini menunjukkan bahwa responden perempuan etnis Bali telah memiliki pengalaman yang cukup menjadi pekerja yang profesional. Sebagian besar responden (44\%) memiliki jumlah anak2 orang. Kemudian 33\% responden memiliki hanya satu orang anak. Jika dikaitkan dengan umur responden yang relative muda maka hal ini menunjukkan bahwa perempuan etnis Bali dengan pasangan mereka lebih cenderung untuk memiliki anak yang relative sedikit. Sementara jika melihat pekerjaan yang dilakukan sebagian besar responden perempuan etnis Bali bekerja di sektor swasta (67\%) sebagai seorang karyawan. Bekerja di sektor swasta tentu membutuhkan komitmen yang tinggi dari para perempuan etnis Bali untuk bekerja dengan sebaik-baiknya.

Hasil pengujian hubungan antar variabel penelitian dapat dilihat dari nilai koefisien jalur dan titik kritis ( $\mathrm{t}$ statistic) yang signifikan pada ${ }^{\circ}=0,05$. Bila hasil pengujian hipotesis pada outer model signifikan, menunjukkan bahwa indikator dipandang dapat digunakan sebagai instrumen pengukur variabel laten, sedangkan bila hasil pengujian pada inner model signifikan berarti terdapat pengaruh yang bermakna antara variabel laten.

Tabel 4.12. Hubungan Antar Variabel (Pengaruh Langsung)

\begin{tabular}{|c|l|c|c|c|c|}
\hline Hipotesis & $\begin{array}{c}\text { Hubungan } \\
\text { Antar } \\
\text { Variabel }\end{array}$ & $\begin{array}{c}\text { Koefisien } \\
\text { Jalur }\end{array}$ & t-Statistik & P Value & Kesimpulan \\
\hline H1 & $\begin{array}{l}\text { WFC } \rightarrow \\
\text { KK }\end{array}$ & $-0,501$ & 6,960 & 0,000 & Signifikan \\
\hline H2 & WFC $\rightarrow$ KH & 0,388 & 4,966 & 0,053 & Signifikan \\
\hline
\end{tabular}

Sumber: Data Primer Diolah, 2017

Berdasarkan tabel 4.12. di atas dapat dijelaskan:

a. Nilai koefisien jalur dari WFC (X) ke kepuasan kerja (Y1) sebesar -0,501 menunjukkan bahwa WFC berpengaruh negatif terhadap kepuasan kerja, dan pengaruhnya signifikan (nilai t-statistik 6,960). Maka dapat disimpulkan bahwa terdapat pengaruh yang negatif antara konflik pekerjaan keluarga terhadap kepuasan kerja.

b. Nilai koefisien jalur dari WFC (X) ke kepuasan hidup (Y2) sebesar -0,388 menunjukan bahwa WFC berpengaruh negatif terhadap kepuasan hidup dan signifikan (nilai tstatistik 4,966). Maka dapat disimpulkan bahwa terdapat pengaruh negatif dan signifikan antara konflik pekerjaan keluarga terhadap kepuasan hidup.

Konflik pekerjaan keluarga memengaruhi beberapa hal yang berkaitan dengannya, salah satunya dengan kepuasan kerja. Kepuasan kerja menjadi salah satu dampak paling banyak diteliti di dalam literatur konflik pekerjaan keluarga (Grandey, Cordeiro, \& Crouter, 2005). Hubungan yang diperkirakan terjadi antara konflik pekerjaan keluarga dengan kepuasan kerja adalah konflik pekerjaan keluarga yang tinggi akan menurunkan kepuasan kerja (Salguero et al., 2010). Kepuasan kerja adalah sikap yang berkaitan dengan sejauh mana orang akan menyukai atau tidak menyukai pekerjaan yang mereka lakukan (Spector,1997).

Sebagian besar penelitian terdahulu menemukan hasil bahwa konflik pekerjaan keluarga memengaruhi kepuasan kerja secara negatif. Sehingga temuan penelitian ini mendukung hasil penelitian terdahulu tersebut. Penelitian Karimi, Jomehri, Asadzade, dan 
Sohrabi (2012) menunjukkan hasil bahwa konflik pekerjaan keluarga berpengaruh negatif terhadap kepuasan kerja. Gangguan yang tinggi diantara domain pekerjaan dan domain keluarga menjadi sebab kepuasan kerja yang rendah. Demikian juga hasil penelitian Zhao \& Namasivayam (2012), Rantika dan Sunjoyo (2011), Wang et al., (2010), Zhao dan Qu (2009), menunjukkan hasil bahwa konflik pekerjaan keluarga memengaruhi kepuasan kerja secara negatif.Kossek dan Ozeki (1998) berpendapat bahwa konflik pekerjaan keluarga berpengaruh negatif terhadap pekerja, dimana pekerja menjadi sering absen, motivasi untuk melakukan pekerjaan rendah, prestasi kerja menurun dan kepuasan kerja rendah. Konflik pekerjaan keluarga bersifat psikologis, seperti timbul rasa bersalah, gelisah, cemas dan frustasi yang menurunkan kesehatan fisik dan mental ibu bekerja (Hewlett, 2003 dalam Triwahyuni, 2009). Hasil ini akan merugikan tempat perempuan bekerja, karena akan menurunkan kualitas sumberdaya manusia, kepuasan kerja menurun dan sering tidak masuk kerja.

Terkait dengan perempuan etnis Bali yang bekerja, konflik pekerjaan keluarga yang dialami oleh perempuan etnis Baliakan berpengaruh terhadap kepuasan kerja mereka. Perempuan etnis Bali yang bekerja, di saat mencoba untuk menyeimbangkan perannya di keluarga, di pekerjaan maupun peran mereka dalam kegiatan agama/adat tentu tidak luput dari konflik pekerjaan keluarga. Perempuan etnis Bali akan berusaha untuk memenuhi peran mereka yang saling berbenturan pada saat yang bersamaan. Perempuan etnis Bali harus menyelesaikan tugas-tugas mereka di domain keluarga seperti mengasuh anak, mengurus suami, dan menyelesaikan pekerjaan rumah tangga. Mereka juga harus menyelesaikan tugas-tugas agama/adat dan bekerja.

Upaya penyeimbangan peran pekerjaan dan keluarga memecah waktu dan energi yang dibutuhkan untuk melakukan pemenuhan peran di pekerjaan dan aspek kehidupan keluarga yang penting lainnya.Oleh sebab itu, individu yang tidak meraih keseimbangan dalam menjalankan peran-perannya dapat kehilangan semangat untuk melakukan pekerjaannya (Parkes \& Langford, 2008 dalam Kesumaningsari \& Simarmata, 2014). Hal ini menyebabkan kepuasan kerja perempuan bekerja menjadi rendah.

Seringkali perempuan etnis Bali harus absen dari bekerja untuk memenuhi tanggung jawab mereka pada keluarga maupun tanggung jawab mereka terhadap kegiatan agama/adat. Semakin tinggi tingkat konflik pekerjaan keluarga yang di alami perempuan etnis Bali maka mereka menjadi semakin tidak puas dalam melakukan pekerjaan mereka. Apalagi ketika menghadapi kondisi kerja yang menerapkan reward dan punisment secara ketat, menyebabkan semakin tinggi konflik peran perempuan karena akan semakin cemas bagi yang bersangkutan bila tidak bisa mengerjakan pekerjaan pada pekerjaan domestik (adat, agama, dan rumah tangga) (Saskara, 2012).

Terjadinya konflik antara urusan domestik dengan pekerjaan sesuai dengan temuan Susanna Lo et al. (2003), dan Yang, et al. (2000) dalam Saskara (2012), bahwa konflik pekerjaan dan keluarga merupakan problem signifikan bagi banyak perempuan profesional yang telah menikah. Hal itu senada dengan pendapat Kulik dan Faisal (2006, dalam Saskara, 2012) yang menyatakan bahwa banyak profesional perempuan menikah merasa 
tidak bebas melaksanakan tugas di tempat kerja.Sehingga hal tersebut akan menyebabkan kepuasan kerja yang rendah bagi perempuan etnis Bali yang bekerja.

Kepuasan hidup didefinisikan secara khas sebagai tingkatan di mana penilaian individu terhadap kualitas hidup mereka yang menyenangkan dan hal ini dapat disamakan dengan kebahagian (Veehoven, 1991 dalam Kadir, 2001). Sementara Adepoju (2017) menyatakan kepuasan hidup adalah komponen subjektif dari kesejahteraan seseorang yang terdiri dari penilaian kognitif terhadap kehidupan seseorang secara keseluruhan. Sedangkan menurut Diener, Emmons, Larsen, dan Griffin (1985 dalam Adepoju, 2017)), kepuasan hidup adalah tentang mempertimbangkan sistem nilai sendiri ketika membuat penilaian terhadap berbagai elemen kehidupan lainnya secara keseluruhan. Bukti menunjukkan bahwa ada aspek emosional, sosial, dan fisik dari kepuasan hidup yang saling bergantung (Cloninger \& Zohar, 2011 dalam Adepoju, 2017).

Para peneliti sering menganggap kepuasan hidup, kebahagiaan secara positif dan negatifnya terdiri dari konsep yang sama, di beri nama sebagai kesejahteraan subjektif (Diener, 1984; Veehoven, 1991 dalam Kadir, 2001). Kepuasan hidup, menurut definisi, unik bagi individu yang menentukannya. Meski ada beberapa kesepakatan tentang kualitas penting yang memengaruhi kepuasan hidup (misalnya, hubungan kesehatan dan kesuksesan), individu pada akhirnya menentukan faktor-faktor ini untuk dirinya sendiri dan memberikan nilai bagi mereka (Diener, et al., 1985 dalam McMillan,2011). Bagi sebagian besar individu kepuasan hidup adalah tujuan akhir hidup. Bila seseorang bahagia dan perasaan positifnya melebihi perasaan negatifnya dalam kehidupan sehari-hari, ini akan memberi kontribusi positif terhadap kepuasan hidupnya.

Konflik antara pekerjaan dan keluarga dapat mengarah pada stress dalam bekerja karena konflik pekerjaan keluarga ini memaksa seseorang untuk memerankan perilaku yang bertentangan dengan wewenang yang berbeda. Kegiatan keluarga berperan dalam menentukan kepuasan hidup, maka ketika pekerjaan sangat memengaruhi aktivitas keluarga akibatnya adalah kepuasan hidup yang rendah. Oleh karena itu konflik pekerjaan keluarga akan memengaruhi kepuasan hidup secara langsung. Wanita karier yang merasa pekerjaannya mencampuri kehidupan keluarganya melaporkan kepuasan hidup yang lebih rendah daripada wanita karier yang merasa tidak ada pengaruh tersebut (Kadir, 2001).

Berkaitan dengan perempuan etnis Bali yang bekerja, ternyata semakin tinggi konflik pekerjaan keluarga yang dirasakan akan membuat semakin rendah tingkat kepuasan hidup. Hal ini karena kegiatan keluarga berperan dalam menentukan kepuasan hidup (Near, Smit, Rice \& Hunt, 1984; Veehoven, 1991 dalam Kadir, 2001). Ketika pekerjaan mememgaruhi kehidupan keluarga, maka konflik akan sering muncul dalam keluarga yang menyebabkan rendahnya kecocokan perkawainan di mana hal ini akan menyebabkan rendahnya tingkat kepuasan hidup (Bedean et all, 1988, Parasuraman et all, 1992). Temuan penelitian ini konsisten dengan beberapa temuan dari beberapa peneliti seperti Erdamar dan Damirel (2016); McMillan, (2011), Yucel (2016), dan Kadir (2001) yang menemukan bahwa konflik pekerjaan keluarga berpengaruh negatif terhadap kepuasan hidup. Pekerjaan dan keluarga merupakan komponen utama kehidupan seseorang. Sehingga ke dua domain 
tersebut berdampak pada kepuasan hidup seseorang. Konflik pekerjaan keluarga berhubungan negatif dengan kepuasan hidup. Bila seseorang tidak mampu melaksanakan tugas tepat waktu atau tidak dapat membuktikan diri sebagai yang terbaik, dimana pekerjaan menganggu kehidupan keluarga, maka ketidakseimbangan yang terjadi menghasilkan stress dan ketidakpuasan hidup (Nawab \& Iqbal, 2013). Sehingga semakin tinggi konflik antara pekerjaan dan keluarga, semakin rendah kepuasan hidup.

\section{KESIMPULAN DAN SARAN}

Kesimpulan penelitian ini adalah: Konflik pekerjaan keluarga (WFC) memengaruhi secara negatif kepuasan kerja perempuan etnis Bali yang bekerja di Kota Mataram. Konflik antara pekerjaan dan keluarga yang dihadapi oleh perempuan etnis Bali yang bekerja dapat memengaruhi perasaan senang atau tidak senang mereka terhadap pekerjaan dan Konflik pekerjaan keluarga (WFC) memengaruhi secara negatif kepuasan hidup perempuan etnis Bali yang bekerja di Kota Mataram.Perempuan etnis Bali yang bekerja yang mengalami kesulitan dalam menyeimbangkan perannya di pekerjaan maupun di keluarga akan memiliki kepuasan hidup yang rendah. Sementara saran yang dapat disampaikan adalah:Konflik pekerjaan keluarga yang di alami oleh perempuan etnis Bali yang bekerja berada pada tingkat sedang. Jika hal ini tidak mampu dikelola dengan baik akan menjadi penyebab semakin tingginya tingkat konflik pekerjaan keluarga pada perempuan etnis Bali. Oleh karena itu diharapkan perempuan etnis Bali dapat menyeimbangkan peran mereka antara pekerjaan dan keluarga; Kepuasan kerja dan kepuasan hidup pada perempuan etnis Bali diharapkan untuk dapat ditingkatkan seiring dengan kemampuan mereka menyeimbangkan peran di pekerjaan dan di keluarga; Perlu dilakukan penelitian terhadap variabel-variabel dalam model ini dengan responden yang lebih heterogen dari segi etnis/budaya untukmeningkatkangeneralisasidaritemuanpenelitian; Pengumpulan data perlu ditambah dengan wawancara kepada subyek penelitian agar data primer yang didapat benar-benar menjelaskan keadaan yang sebenarnya.

\section{DAFTAR PUSTAKA}

Adepoju, Anthony, 2017, Exploring the Role of Work-Family Conflict on Job and Life Satisfaction for Salaried and Self-Employed Males and Females: A Social Role Approach, Dissertation, Georgia State University, 2017.

Amat,Salleh, Mahmud, Zuria, 2009, Hubungan antara Ketegasan Diri dan Kepuasan Hidup Dalam Kalangan Institusi Pengajian Tinggi, Jurnal Pendidikan Malaysia 34 (2)(2009):49-65

Bedeian,Arthur G, Burke, Beverly G, Moffett, Richard G, Outcomes of Work-Family Conflict Among Married Male and Female Profesionals, 1988, Journal of Management Vol. 14, No. 3 
Bruck,Carly S, Allen,Tammy D, Spector, Paul E, 2002, The Relation Beetween WorkFamily Conflict and Job Satisfaction: Afiner-Grained Analysis, Journal of Vocational Behavior 60, 336-353 (2002)

Eid, Michael, Larsen, Randy J, 2008, The Science of Subjective Well-Being This is a chapter excerpt from Guilford Publications

Diener, E., Emmons, R. A., Larsen, R. J., \& Griffin, S, 1985, The satisfaction with life scale. Journal of Personality Assessment, 49, 71-75.

Diputra, NyomanDitaWira, Lestari, Made Diah, 2015, Koping Stres Dalam Menjalani Peran Ganda Pada Wanita Hindu di Denpasar, JurnalPsikologiUdayana2015, Vol. 2, No. 2, 206-214

Erdamar, Gürcü, Demirel, Hüsne, 2016, Job and Life Satisfaction of Teachers and the Conflicts They Experience at Work and at Home, Journal of Education and Training Studies, Vol. 4, No. 6; June 2016

Grandey, Alicia A., Cordeiro, Bryanne L., Crouter, Ann C, 2005, A longitudinal and multisource test of the work-family conflict and job satisfaction relationship, Journal of Occupational and Organizational Psychology (2005), 78, 1-20

Greenhaus, Jeffrey H, Beutell, Nicholas J, 1985, Sources of Conflict Between Work and Family Roles, Academy of Management Review, 10,76-88

Hasan, Zaiton, Dollard, Maureen F., Winefield, Anthony H., 2010, Work-Family Conflict East vs Western Countries, Cross Cultural Management an Internasional Journal, Vol 17 No 1 pp 30-49

Hsu, Yu Ru, 2011, Work-Family Conflict in Sressful Working Environment: The Moderating Roles of Perceived Supervisor Support and Internal Locus of Control, Internasional Journal of ManpowerVol 32, Issue 2, Page 233-248

Kadir, Abdul Rusli,2001, Pengaruh Karier, Konflik Pekerjaan-Keluarga Terhadap Kepuasan Hidup Wanita Karier di Jawa Tengah dan Yogyakarta,Tesis program Studi MM Pascasarjana Uiversitas Diponegoro,Semarang.

Karimi, Qumarth , Jomehri, Farhad , Asadzade, Hasan , Sohrabi, Faramarz, 2012, Consequences of Conflict between Work and Family among Iranian Female Teachers, Journal of Basic and Applied Scientific Research, 2(2)1869-1875, 2012

Kesumaningsari, Ni Putu Adelia, Simarmata, Ncholas, 2014, Konflik Kerja-Keluarga dan Work Engagement Karyawan Bali Pada Bank di Bali, Jurnal Psikologi Udayana, Vol 1,No.3, 493-506

Kossek, Ellen Ernst, Ozeki, Cynthia, 1998, Work-family conflict, policies,and the job-life satisfaction relationship: A review and directions for organizational behaviorhuman resources research,Journal of Applied Psychology vol 83 pp139-149 
McMillan, Heather S, 2011, Examining the Relationship between Work/Life Conflict and Life Satisfaction in Executives: The Role of Problem-Focused Coping Techniques, University of Tennessee, KnoxvilleTrace: Tennessee Research and Creative Exchange

Michel, Jesse S., Hargis, Michael B.,2008, Linking mechanisms of work-family conflict and segmentation, Journal of Vocational Behavior 73 (2008) 509-522

Nawab, Samina, Iqba,1 Sana, 2013, Impact of Work-Family Conflict on Job Satisfaction and Life Satisfaction, Journal of Basic and Applied Scientific Research., 3(7)101110,2013

Qu,Hailin, Zhao, Xinyuan (Roy), 2012, Employees' work-family conflict moderating life and job satisfaction, Journal of Business Research 65 (2012) 22-28

Rantika, Renny, Sunjoyo, 2011, Pengaruh Konflik Kerja-Keluarga Terhadap Komitmen Organisasional Yang Dimediasi Oleh Kepuasan Kerja Pada Profesi Perawat di Rumah Sakit Umum Daerah (RSUD) dr. Moewardi Surakarta, Jurnal Manajemen Teori dan Terapan | Tahun 4, No. 2, Agustus 2011

Salguero, Calvo Antonia et.al, 2010, Relationship Between Work-Family Conflict and Job Satisfaction:The Moderating Effect of Gender and The Saliance of Family and Work Roles, African Journal of Business Management Vol.4(7), pp. 1247-1259, 4 July, 2010.

Saskara, Ida AyuNyoman, Pudjihardjo, Maskie, Suman, 2012, Tinjauan Perspektif Ekonomi dan Nonekonomi Perempuan Baliyang Bekerja di SektorPublik: Studi Konflik Peran, jurnal jam.ub.ac.id > Home > Vol 10, No 3 (2012)

Seng, Adriel Sam Khoon, Bujang, Sopian B, Rusli, Ahmad, 2009, Work-Family Interface: The Relationship Between Work-Family and Religious Support and Its Influence on Job, Family And Life Satisfaction, Paper submitted to BAI 2009 International Conference on Business \& Information, Kuala Lumpur.

Siagian, S.P., 2003. ManajemenSumberDayaManusia, CetakanKetujuh, BumiAksara, Jakarta

Spector, Paul E, 1997, Job Satisfaction, Application,Assessment,Couse, and Consequences, SAGE Publications, USA

Triwahyuni, Bunga, 2009, Dual Role Conflict Relationship with Satisfaction Work on the Married Women Teachers, papers. gunadarma.ac.id/index.php/psychology/ article/download/.../915

Parasuraman, Saroj, Greenhaus, Jeffrey H., Granrose, Cherlyn Skromme, 1992, Role stressors, social support, and well-being among two-career couples, Journal of Organizational Behavior, Volume 13, Issue 4 
Wang, Peng, Lawler, John J., Shi, Kan, 2010, Work-Family Conflict, Self-Efficacy, Job Satisfaction, and Gender: Evidences From Asia, Journal of Leadership \& Organizational Studies 17(3) $298-308$

Wafula, Anne Nasambu, 2010, Work-Family Conflict Among Women From a Collectivistic Culture, MA minithesis, Department of Industrial Psychology, University of the Western Cape

Waskito, Jati, H. Irmawati, 2007, Perbedaan Gender Dan SikapTerhadapPeranPekerjaanKeluarga: ImplikasinyaPadaPerkembanganKarirWanita, BENEFIT,Vol. 11, No. 1, Juni 2007

Widayani, M. D. \&Hartati, S. (2014). Kesetaraan dan Keadilan Gender dalam Pandangan Perempuan Bali: Studi Fenomenologis Terhadap Penulis Perempuan Bali. Jurnal Psikologi Undip, 13(2), 149-162

Yucel, Deniz, 2016, Work-To-Family Conflict and Life Satisfaction: the Moderating Role of Type of Employment, Applied Research Quality Life, DOI 10.1007/s11482-0169477-4 2016

Yudarta, I Gde, 2011, Kehidupan Masyarakat Bali di Kota Mataram, www.isidps.ac.id/berita/kehidupan-masyarakat-bali-di-kota-mataram/

Zhaoa, Xinyuan, Qu, Hailin, 2009, A Study on the Impacts of Work-Family Conflict on Job and Life Satisfaction among Hotel Sales Managers in China, Published by ScholarWorks@UMass Amherst,2009

Zhaoa, Xinyuan (Roy), Namasivayam, Karthik, 2012, The Relationship of Chronic Regulatory Focus to Work-Family Conflict and Job Satisfaction, International Journal of Hospitality Management 31 (2012) 458-467 